\title{
Stirling-powered solar dish collector with compressed air energy storage system
}

\author{
Giovanni Ricco \\ BSS Ltd F/7, Building No. 5, Shijijiayuan, Beijing 100029 P. R. China.
}

\begin{abstract}
At present time, the SE applied to solar dish reflectors is not competitive compared to other concentrated solar power technologies because Stirling CSP equipment has complex and expensive engines and does not have a proper energy storage system. This paper introduces Stirling solar dish technology, proposes a layout of a simple SE with compressed air storage system, and examines the total performance of the equipment.
\end{abstract}

\author{
Abbreviations \\ CSP Collector Solar Plant \\ PLC Programmable Logic Computer \\ PSV Pressure Safety Valve \\ SE Stirling Engine
}

\section{Introduction}

The Stirling-powered solar dish collector is not a new technology. It produces power by thermodynamic cycle; many attempts to design and manufacture acceptable equipment have been made in the past and are still ongoing. The idea is based on a hot air engine properly located in the focus centre of a parabolic reflector that is heated directly by concentrated sunrays. The engine supplies mechanical torque when there is sufficient differential temperature between its hot and cold sides. The engine could be fitted with a storage system and dedicated generator to produce power. This way of producing power is not economical compared to photo voltaic and other CSP technologies. Below are listed some typical positive and negative points about the Stirling-powered solar dish collector.

Advantages:

- Stirling solar collectors do not need pipes, pumps, and other elements for operation, only power cables and control wires are required. The system is easy to scale up and to update with new technologies.

Disadvantages: 
- The output energy is electric energy; therefore, the user has to consume electricity at the same time as generation, otherwise it is necessary to include dedicated energy storage equipment that makes the system much too expensive.

- Every solar collector needs a dedicated engine, which make the equipment expensive for small dishes less than $5 \mathrm{~m}$ diameter.

\section{Stirling Solar Dish description}

The SE (or hot air engine) is normally assembled with a parabolic dish solar collector. Sunrays are collected by the parabolic dish and then reflected to heat the hot side of the engine. The power module is located in the centre of the collector with a dedicated frame according to dish optical focus length. The frame has to support the engine with its power generator. This power module is located 3-5 meters from the parabolic dish collector. It is a heavy and complex part of the equipment shown in Fig.1.

Inside the power module is also located the control cabling, circuits, and power cable to supply electrical energy.

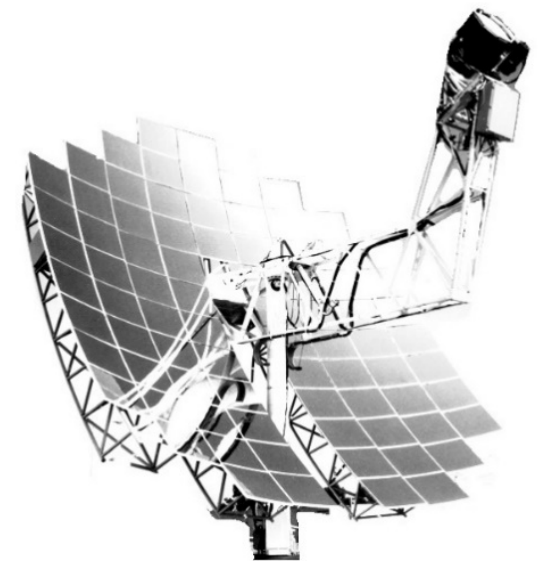

Figure 1. Typical arrangement of power module.

\section{Guidelines}

The design guidelines for the project are set to overcome the typical limitations of Stirling solar dish technology. The main point is not to find the best performance of the engine but to make it feasible with basic technologies by non-specialized manufacturers. It is fact that top managers do not want to invest in SE technology. The target of this work is to design concentrated solar equipment to supply power for a house with four people that is easy to scale up for an off-grid power plant. The equipment has to supply $20 \%$ of energy from daylight and $80 \%$ from its storage system.

The location of the solar dish taken in consideration is latitude of $39.92^{\circ}$, equivalent to cities like Beijing, Rome, and Madrid, which affects the sunray incidence. Sun data from the ENREL [3] database shows the maximum solar light incident is: $1000 \mathrm{~W} / \mathrm{m} 2$.

The equipment has to be economical for middle and small manufacturers. Companies have problems finding workers with proper skills and backgrounds to design and manufacture this 
equipment, therefore it's a main point that the design has to consider oil and gas manufacturers that want to convert their production to CSP. To comply with these points, the engine has to be mounted on the back of a dish collector to avoid the support frame for the module it is located on center of focus of the parabolic dish. The engine will follow the Stirling beta type scheme, where only one cylinder is required but two pistons are inside one loose (displacer) and the other acting as the power piston (see Fig. 3).

The design has to be easy to understand. This is a very critical point for upper management, who need to feel comfortable with an engine that is not common in their eyes. Although a rhombic drive or a linear engine is simpler to manufacture, a classic $90^{\circ}$ crankshaft and related rods were selected because they are a well-known technology.

For ease of installation, the size of the equipment has to be as small as possible and installation and maintenance has to be easy to perform at any step.

Simplifying the layout reflects the costs and type of production. Also, we have to consider that all workers have to understand easily how the system is intended to work.

While meeting the above points, the equipment has to get the best efficiency possible.

The energy storage included in the equipment has to make the equipment a good investment for industries and a more reliable solution.

\section{Project layout}

The equipment has the following elements as shown in Fig.2.

The reflective dish with its steel frame support is double hinged for proper solar tracking. The dish is moved by two motors; one rotates the dish according to the time of day (azimuth) and the other moves the mirror following the seasonal movement of the earth. To reduce the cost of solar tracking, the equipment was not provided sensors but uses only satellite data and PLC to rotate the dish according to latitude-longitude location. When the sun is at the top of the midday sky, the axial motor will rotate the dish $180^{\circ}$ to continue to follow the sun because the engine could get interference from the column of dish. The solar dish was manufactured with carbon steel wire mesh to be stitch welded with plasma cut plates (see Fig. 2). Mirror film was properly glued to its location, and to ensure it works properly a light torch was used to check the correct reflection of rays to the centre of the focus location. The solar dish was provided with double reflectors. The main one is a classic parabolic dish that shares the centre of focus with one of the secondary hyperbolic reflector as shown in "Annex A". With the use of two mirrors, energy conversion efficiency will be reduced a little, but the structure will be simpler than other solar dishes Fig.2. 


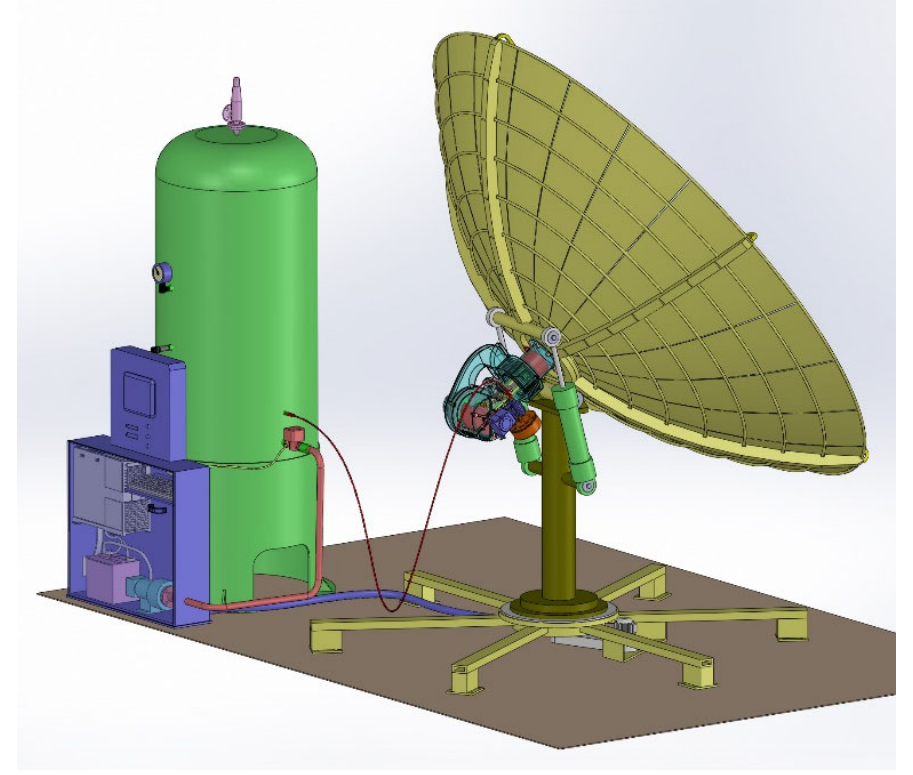

Figure 2. Layout of the equipment.

The engine is located near the centre of mass of the dish, close to the horizontal solar-tracking hinge (see Fig. 3). The second reflector is a hyperbolic revolution mirror that is easier to manufacture than a small parabolic dish due its convex shape.

The SE and its pneumatic compressor are shown in Fig.3. A beta type SE was selected. Its working volume is one liter, and the crankshaft was designed and balanced, so it requires only two bearings, thereby reducing friction and making it easier to produce "Annex B". The engine was filled with air at atmospheric pressure and designed to work at maximum pressure of 6barg, which is quite safe and easy to handle. The mechanical output power target is 2.2 $\mathrm{kW}$ at $3000 \mathrm{rpm}$ when the reflector gets maximum solar irradiation. In case of higher output, power required by the engine may be filled with compressed air from the storage vessel by a dedicated control valve. The minimum differential temperature of the engine working fluid is $50^{\circ} \mathrm{C}$ and maximum is $400{ }^{\circ} \mathrm{C}$. The hot side of the engine has a plate bolted directly to the sunray focus location of the hyperbolic reflector to concentrate the sunlight at one point. The heads of the displacer and the cylinder are flat to simplify the production. A heat regenerator was not actually included to reduce cost, save manufacturing time, and make it simpler to setup for proper operation. The engine has a fan directly mounted on its shaft that cools the cold side of the engine to increase the performance. Additionally, oil lubricant was used to cool the bottom head of the power piston. The oil lubricant does not require a dedicated pump; it wets the internal side of the power piston and cylinder by crankshaft movement. A pneumatic compressor was mounted to the other side of engine shaft. The pneumatic compressor is a common module and has the double function of starting the engine by the residual compressed air from the storage vessel. The engine and the compressor were bolted to the back of the solar dish as shown in Fig.3. 


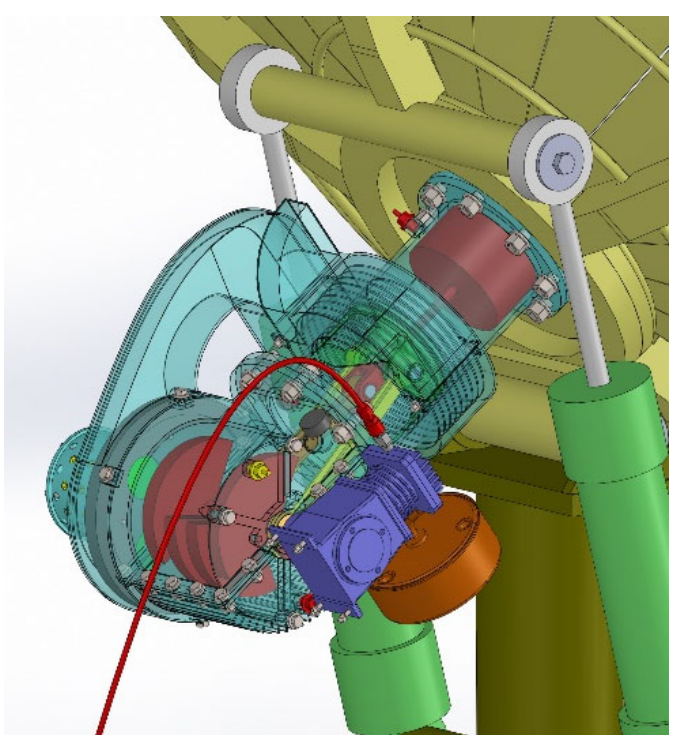

Figure 3. Stirling engine $\beta$ type.

The compressed air vessel with PSV and valves is shown in Fig.2. A vertical vessel designed with pressure of $50 \mathrm{bar}(\mathrm{g})$ was piped directly to the compressor and to the expander turbine operated by two automated valves. The volume of the vessel was 1050 liters, enough to store energy for a full working day of the solar dish according to the isothermal compression formula (1):

$$
W=p B * v B * \ln \left(\frac{p A}{p B}\right)+(p B-p A) * v B=8.7 k W h
$$

where $p A, p B$ are start and end pressure, $v A, v B$ are start and end volume, respectively, and energy value has to be corrected according to thermo-mechanical energy loss.

The turbo expander [4] linked by a dedicated shaft to a power generator is shown in Fig.4. Inside the case is the control panel of the equipment, and the turbo expander and power generator are directly mounted on its shaft with max output power of $3 \mathrm{~kW}(\mathrm{e})$.

The local control panel includes a programmable PLC with monitor, keyboard, and $12 \mathrm{~V}$ back-up battery; the equipment is self-sufficient and does not need an external power supply.

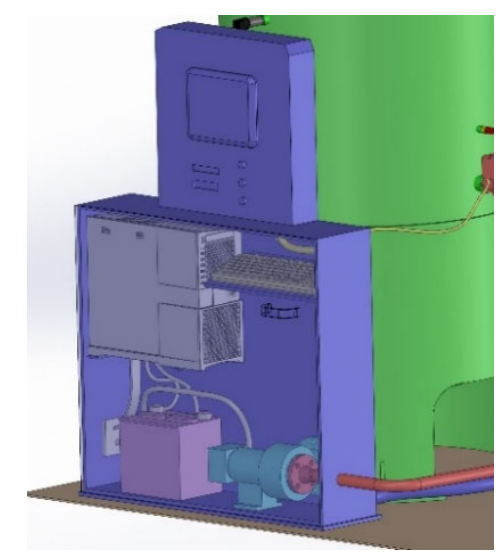

Figure 4. Local control panel with turbo expander module. 


\section{Operation}

The solar dish revolution axe is aligned to the sun by its solar-tracking devices and data table by the PLC. Sunrays are collected from the $3 \mathrm{~m}$ dish to the secondary mirror, where the rays are reflected to the centre of the main dish as shown in "Annex A". The concentrated sunrays heat the hot end of the SE. When a sufficient differential temperature between hot and cold engine elements has been reached, the PLC opens a valve and sends pressure to the compressor. Due its reversible capability, the compressor may work as a compressed air starter to start-up the SE. The PLC closes the start-up valve and opens slightly the outlet valve. The engine delivers the compressed air to the vessel by its compressor. At the end of the day, the pressure of the compressed air in the vessel will be 50 bar(g). When a user requires power, the PLC opens the output valve to the turbo expander and produces power by a generator mounted on its shaft.

The PLC may deliver power also during daylight. By bypassing the pressure vessel storage, the compressed air will be directed to the turbo expander to produce power. The SE was designed to work at atmospheric pressure but if required the PLC may increase the power output with higher working fluid mass. A simplified schematic operation diagram of the information described above is shown in Fig.5.

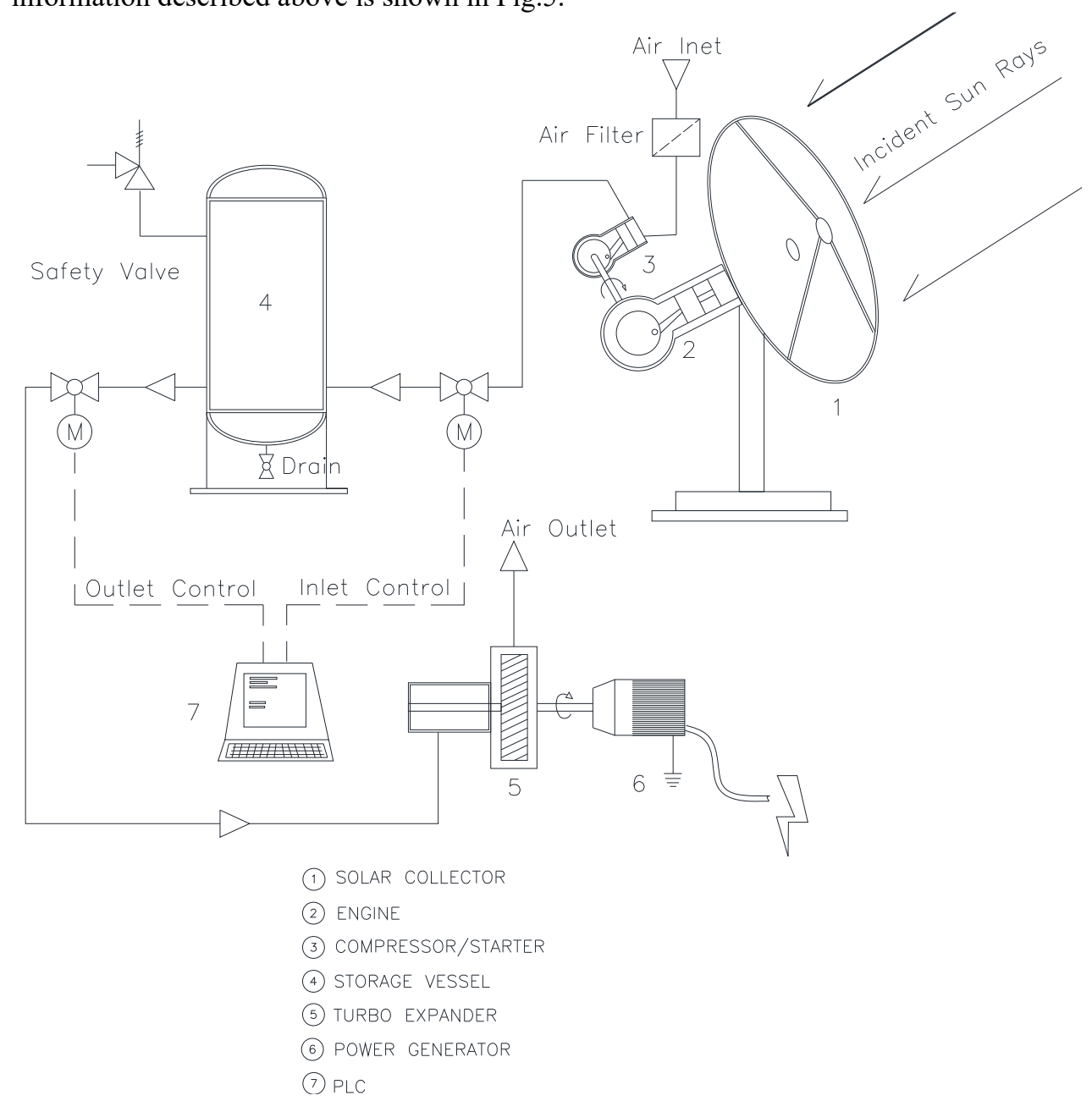

Figure 5. Operation scheme. 


\section{Performance}

The engine was designed according to Schmidt's theory [2] described in Martini's book on second order design [1]. Proper balancing of the crankshaft was done by dynamic analysis ANSYS software. Additionally, computational fluid dynamics analysis was performed by Fluent software to check the consistency of the thermodynamic design see "Annex C". The compressed air vessel was designed according to ASME VIII Div. 1. The expansion turbine has a typical efficiency of $80 \%$ and maximum output power of $5 \mathrm{~kW}$.

The equipment has total efficiency of $21 \%$ of sunray incident energy. The equipment here described is in the prototype stage of manufacture in Handan City, China. Its performance meets the requirements described in the Design Guidelines (Section 4) of this paper. The main challenge concerns balancing the rotational speed of the engine with the compressor directly mounted on its shaft. Different ways to get constant mechanical torque were taken in consideration. The best solution could be to change dynamically the internal working pressure of the SE but other solutions to the matter are still in progress.

\section{Future development}

A simple energy regenerator will be inserted in the displacer. To increase engine efficiency, the hot air will pass through it to transfer heat by stainless steel wires. The solar dish will be updated with a proper electrical starter/generator so that it does not require residual pressure inside the storage tank to start the SE. The starter working as a generator may deliver energy during daylight without the necessity of bypassing the storage vessel, increasing the total conversion efficiency. The engine will be updated with a small back-up gas burner mounted behind the dish close to its hot side to supply thermal energy when sunrays are too weak or totally absent to heat properly the SE.

\section{Scaling up}

The solar dish reflector may be up to a diameter of $5 \mathrm{~m}$ with the same layout and steel structure, updating height and size of pipes and plates. The engine does not need updates because its working speed and fluid working pressure may be increased. The equipment here described with a wider dish reflector will produce a total of $22 \mathrm{kWh}$ per day. The vessel may work with a maximum working air pressure of 100 barg to store the additional energy, and the $5 \mathrm{~kW}$ turbo expander may not require updates because it is able to manage $+50 \%$ of design power for a short time.

Small scale solar field generation is quite simple to perform with this equipment because 2 to 5 solar dishes may share the same air storage vessel. The control panel could manage 10 or more solar dishes and so can the turbo expander.

\section{Conclusion}

Many efficient engines and dish reflectors are interesting but not easy to manufacture and maintain.

The Stirling solar dish still has potential to become one of the most common technologies for renewable energy production. It needs alternative rules and guidelines to target the best balance of simplicity and economy of production as well as producing the best output power. 
The main target of the project here described has met the need to design and manufacture equipment using simple technology that is easy to produce and simple in logic that can be clearly understood by investors, managers, and workers.

\section{References}

1. W. R. Martini - Stirling Engine Design Manual - Richland, Washington -1983

2. K. Hirata - Schmidt Theory for Stirling Engines - www.bekkoame.ne.jp/ khirata - 1997

3. ENREL - National Renewable Energy Laboratory -www.nrel.gov

4. DEPRAG SCHULTZ GMBH (www.deprag.com)

\section{ANNEX A}

\section{RAY REFLECTION}

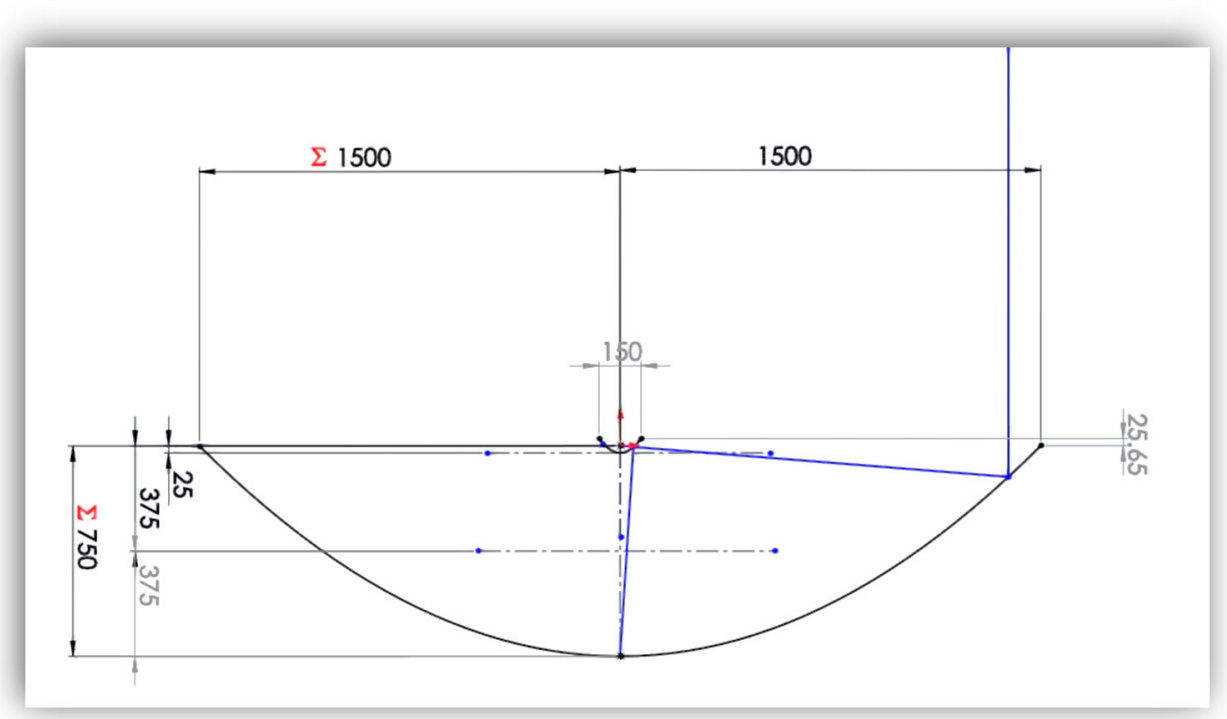


ANNEX B

SOLAR STIRLING ENGINE B TYPE

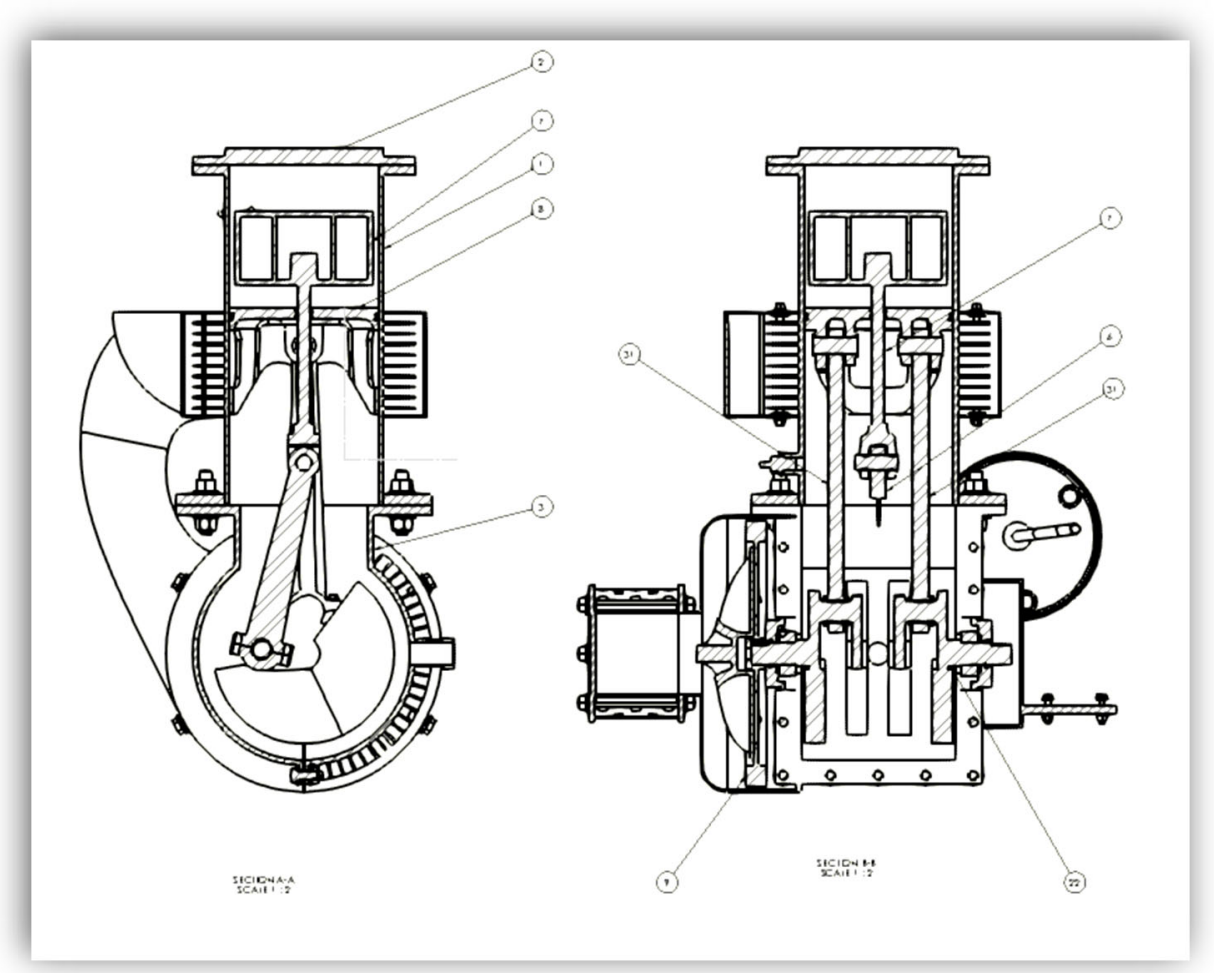


ANNEX C

\section{CFD STIRLING ENGINE}

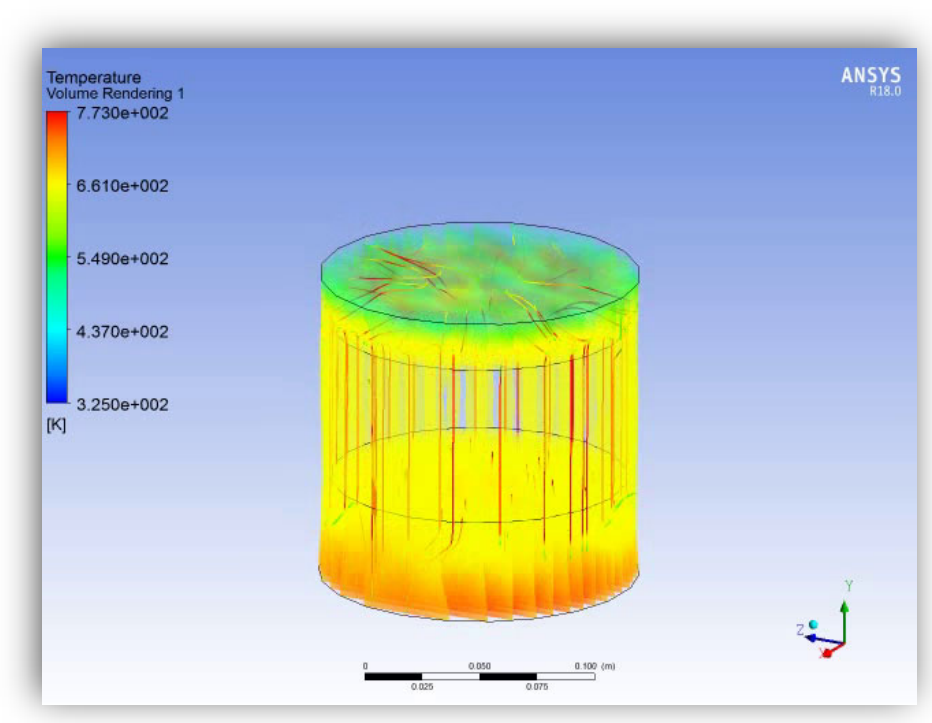

crankshaft angle $=90^{\circ}$

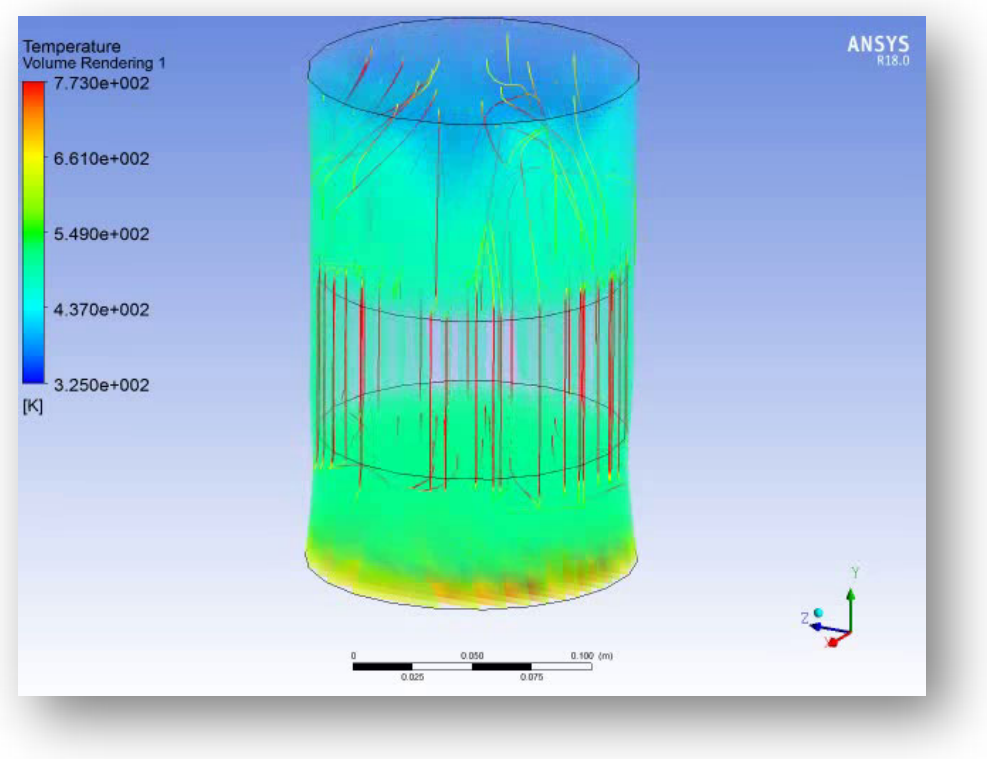

crankshaft angle $=270$ 